\title{
Aspectos do dionisismo na Etrúria: a perpetuação após a morte
}

\author{
ROSELI FELLONE \\ Doutoranda do Departamento de Antropologia \\ Faculdade de Filosofia, Letras e Ciências Humanas \\ Universidade de São Paulo
}

\begin{abstract}
RESUMO: O conjunto da documentação arqueológica etrusca demonstra o destaque dado ao culto de Dioniso em determinadas cidades etruscas bem como a aprovação oficial desses mesmos cultos professados também no âmbito doméstico. Particularmente no século IV a.C. encontramos uma série de vasos que associa elementos dionisíacos com elementos funerários, dando ênfase à condição privilegiada do/a morto/a iniciado/a no dionisismo. Várias outras imagens figuradas nos vasos etruscos do séc. IV a.C. ressaltam o papel exercido pela religião dionisíaca e pelo matrimônio no destino dos mortos, que através da religião e do casamento terão após a morte garantidas a reprodução e a perpetuação de sua história familiar e, por extensão, a história da cidade. PALAVRAS-CHAVE: Etrúria, dionisismo, imagem, cultos, identidade, morte, matrimônio.
\end{abstract}

Em vários vasos etruscos do século IV a.C. encontramos a associação de elementos dionisíacos com elementos funerários. Nestes vasos figuram mulheres adeptas do culto de Dioniso, sendo que tal situação religiosa é indicada pelas insígnias dionisíacas: o tirso, a folha de parreira ou o gesto de abrir o manto como fizeram as Mênades e Ariadne na presença de Dioniso (figuras $1 \mathrm{e} 2$ ).

Todos estes vasos provieram das cidades etruscas do sul, tendo sido alguns deles fabricados nas oficinas das cidades de Vulci e de Falerii. Tanto Vulci como Falerii apresentaram uma documentação arqueológica significativa no tocante aos cultos relativos a Dioniso.

Em Vulci o repertório iconográfico dos vasos, dos espelhos e dos frontões atesta a popularidade das representações de Dioniso e de seu cortejo ${ }^{1}$. Popularidade esta que remonta ao século $\mathrm{V}$ a.C. como nos mostram dois vasos áticos e um de imitação ática da segunda metade do século V a.C., proveniente de Vulci e dedicado a Fufluns Paxies ${ }^{2}$.

Trata-se dos seguintes vasos:

- kylix ática de 455 a.C. do Pintor de Penesilea que apresenta no medalhão interno Apolo lutando com Tício. No lado externo há uma cena de conversação.

A inscrição dedicatória encontra-se sob o pé: fuflunal pax [...];

— kylix ática do século V a.C. figurando um sátiro cavalgando um animal no medalhão interno. Sob o pé da kylix a inscrição dedicatória: fuflunsul paxies valvl $\theta i$;

- rython no formato de cabeça de mula tido como etrusco ou de fabricação indeterminada, datado da segunda metade do século $\mathrm{V}$ a.C.. 
Sobre a alça a inscrição dedicatória: fuflunl paxies velcl $\theta i$.

Fufluns é a forma possessiva da grafia do nome como mostram outros documentos ${ }^{3} \mathrm{e}$ designa a divindade etrusca identificada com o Dioniso ático.

O nome Paxie, segundo Cristofani e Martelli, parece ser o resultado da epíclesis de Dioniso $\beta \alpha \kappa \chi \varepsilon \hat{\imath}$ o conhecido nos cultos dionisíacos de Corinto e Sicione. Velcl $\theta i$ indica o nome da cidade de Vulci, identificado a partir do confronto com os análogos tar $\chi$ nal $\theta i$ que indica "em Tarquínia" e Velsnal $i$ para "em Volsinii"4 . Velci seria, então, a base do nome da cidade de Vulci e velcl $\theta i$ o locativo para "em Vulci".

A assimilação de Fufluns ao Dioniso grego com indicação inscrita do nome encontramos em um espelho prenestino do Museu de Bolonha do segundo quartel do século V a.C.. Neste espelho Fuflunus barbado é figurado junto com Menarva, Artame[s] e Esia ${ }^{5}$.

Entrementes, em um espelho do último quartel do século IV a.C. fabricado em Orvieto ${ }^{6}$, Fufluns é figurado com Vesuna. Vesuna representa a mesma divindade feminina que no panteão de Gubbio é acompanhada por Pomono Popdico. Em Roma também ocorre a associação de Vertumnus-Pomona ${ }^{7}$.

A substituição no espelho etrusco de Pomono por Fufluns "è un chiaro indizio dell'interpretazione di Fufluns comme divinità agreste, interpretazione più che mai motivata $\mathrm{e}$ compatibile nel sito di rinvenimento dello specchio in questione, Orvieto, dove ben documentati sono i culti ctonii e dove é stata verosimilmente favorita altresi dalla vicinanza stessa all'area umbra"8.

Portanto, a integração de Dioniso no panteão etrusco fez-se a partir da divindade agrária Fufluns identificado ao latin Liber e ao umbro Pomono. A figura de Dioniso na Etrúria desenvolveu-se em relação com estes cultos agrários.

Particularmente no que diz respeito a Vulci, os três vasos do século V a.C. confirmam a prática social do culto de Dioniso na cidade e sua ligação com o vinho ${ }^{9}$. Para Cristofani e Martelli ${ }^{10}$ a inscrição dos vasos dedicados a Fufluns - Dioniso exaltam-no como deus do vinho e o nome da cidade inscrito no locativo, Velcl $\theta i$, reveste-se de um interesse econômico, pois Vulci neste período do século $\mathrm{V}$ a.C. é reconhecida por sua produção e exportação de vinho.

Entretanto, F. H. Massa-Pairault ao tratar destes mesmos vasos ${ }^{11}$ acredita que o interesse destas dedicatórias acha-se antes no nível das instituições do que no da economia. Para ela, o

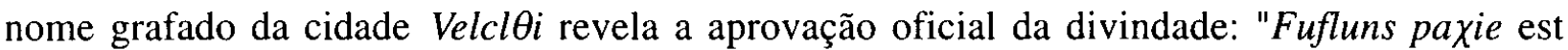
corrélatif de Vulci-communauté et le Fufluns des thiases (paxie évoque l'association plus que le vin) est reconnu par la cité. Les inscriptions proclameraient donc à leur manière l'absence de conflictualité entre l'aspect officiel de la divinité et la pratique sociale privée (familiale, gentilice, ou autre) du dionysisme" ${ }^{12}$. As inscrições dedicatórias dos vasos indicam a existência de thíasoi específicos reconhecidos pela cidade que "sont insérés dans la réalité institutionnelle, soit par l'entremise de fêtes officielles, soit grâce à leur rôle médiateur à l'intérieur de la famille, de la gens,

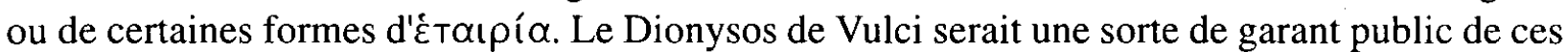
associations"13.

No que se refere a Falerii, já no século VII a.C. a dupla Liber e Ceres simbolizam o mundo da produção e do casamento definidos respectivamente pelo vinho e o farmentum ${ }^{14}$.

A documentação arqueológica etrusca do século IV a.C. confirma a importância dos cultos dionisíacos, sua penetração e adaptação ao mundo do ôkos, ao mundo familiar. Os vasos figurados com cenas funerárias e destinados ao local de sepultamento, demonstram a adesão pessoal do/a morto/a aos aspectos místicos do dionisismo. Aspectos estes desenvolvidos dentro do quadro familiar e do universo feminino. Contudo, o dionisismo além de inserir-se na escultura gentilícea e aristocrática do oîkos também garantida e reconhecida suamanifestação a nível oficial, como vimos nos vasos com inscrição dedicatória do século V a.C.. 
Dentro desse universo familiar e feminino das representações dos vasos etruscos ressalta-se, ainda, a importância do matrimônio: os laços do matrimônio são destacados nos vasos que figuram a separação de Alceste e Admeto (figura 3).

Um outro vaso que figura as Danaides enchendo um pithos, reafirma a importância do matrimônio e o destino de quem rompe ou não consuma as leis matrimoniais (figura 4).

No tocante à representação das Danaides é relevante o detalhe delas assassinarem os maridos na noite de núpcias e, assim, romperem com a instituição do matrimônio. $O$ matrimônio é bastante valorizado na arte funerária etrusca e são comuns as cenas de despedida dos cônjuges separados pela morte. $\mathrm{O}$ episódio de Alceste e Admeto servia como um referencial mítico às cenas usuais de separação e despedida, enaltecendo o amor conjugal e o papel do matrimônio.

Os valores do dionisismo na Etrúria no século IV a.C. fixam-se sobre os valores sociais do casamento: a religiosidade e o matrimônio garantem a perpetuação e a reprodução de uma história familiar.

Os vasos caracterizam-se por serem objetos privados na medida que pertencem ao morto/ a. Quase todos os vasos definem-se como utensílios do banquete, do sympósion, já que são próprios ao vinho. O sympósion realiza-se no ambiente funerário e consagra a presença do vinho.

O dionisismo vincula-se ao mundo familiar, ao mundo do ốkos, e afirma a identidade social e familiar dos seus seguidores, enaltecendo os valores sociais do casamento. Por intermédio do dionisismo e do matrimônio estão garantidas após a morte a perpetuação e a reprodução de uma história familiar e, por extensão, uma história da comunidade, da cidade.

A religião dionisíaca assegura, então, a história da cidade que, por sua vez, garante e oficializa as práticas do dionisismo. O dionisismo na Etrúria do século IV a.C. é reconhecido oficialmente pelas cidades etruscas e vem garantir a perpetuação e reprodução de sua história.

\section{Notas}

1 - Acerca da publicação deste material ver Cazanove, O. obra citada, notas 4 e 5 .

2 - M. Cristofani e M. Martelli trataram detalhadamente destes vasos no seu artigo "Fufluns Paxies. Sugli aspeti del culto di Bacco in Etruria", Studi Etruschi, XLVI, 1978, p. 120-133.

3 - Cristofani e Martelli, no artigo citado, fazem uma listagem de 10 documentos nos quais aparece grafado o nome Fufluns, p. 126-7.

4 - Ibid., p. 128.

5 - Ibid., p. 126, $\mathrm{n}^{\circ} \mathrm{IV}$.

6 - Ibid., p. $126, \mathrm{n}^{\circ} \mathrm{IX}$.

7 - Vesuna é representada em Roma como uma espécie de Mênade e é anterior a Bacchus na tradição dos cultos agrários. Ver Massa-Pairault, F. H. MEFRA 99-2, 1987, p. 584 e notas 25, 26 e 27.

8 - Cristofani-Martelli, obra citada, p. 131.

9 - Os três vasos são recipientes próprios para vinho.

10 - Obra citada p. 132-3.

11 - Massa-Pairault, F. H. "En quel sens parler de romanisation du culte de Dionysos en Étrurie", MEFRA 99-2, 1987, p. 573-594.

12 - Ibid., p. 575.

13 - Ibid., p. 576.

14 - Massa-Pairault, obra citada, p. 577-8. 
a perpetuação após a morte.

\title{
Referências bibliográficas
}

CAZANOVE, O. Plastique votive et imagerie dionysiaque: à propos de deux ex-voto de Vulci. Mélanges d'Archeologie et d'Histoire. École Française de Rome, 98(1): 7-36, 1986.

CRISTOFANI, M. \& MARTELLI, M. Fufluns Paxies. Sugli aspetti del culto di Bacco in Etruria. Studi Etruschi, série III, XLVI: 199-133, 1978.

MASSA-PAIRAULT, F. H. En quel sens parler de la romanisation du culte de Dyonisis en Étrurie. Mélanges d'Archeologie et d'Histoire. École Française de Rome 99(2): 573-594, 2984.

MASSA-PAIRAULT, F. H. Recherches sur l'art et l'artisanat étrusco-italique à l'époque hellénistique. Rome. École Française e Rome, 1985.

FELLONE, R. Aspects of dionysiac cults in Etruria: the perpetuation after death. Classica, São Paulo, 7/8: 111-116, 1994/5.

\begin{abstract}
The Etruscan archaeological documentation reveals the permanence of the cult of Dionysus in some etruscan cities, as well as the official acceptance od such cults in the domestic sphere. Particularly in the IV century b.C. we find a group of vases which associate dionysiac and funerary elements, emphasizing the deceased priviledged condition as an initiate. Many other images in etruscan 4th century vases stress the roles of dionysiac religion and matrimony in afterlife, for by their means the reproduction and perpetuation of the deceased family history, and consequently, that of yhe city, are warranted. KEY WORDS: Etruria, dionysism, image, cults, identity, death, matrimony.
\end{abstract}

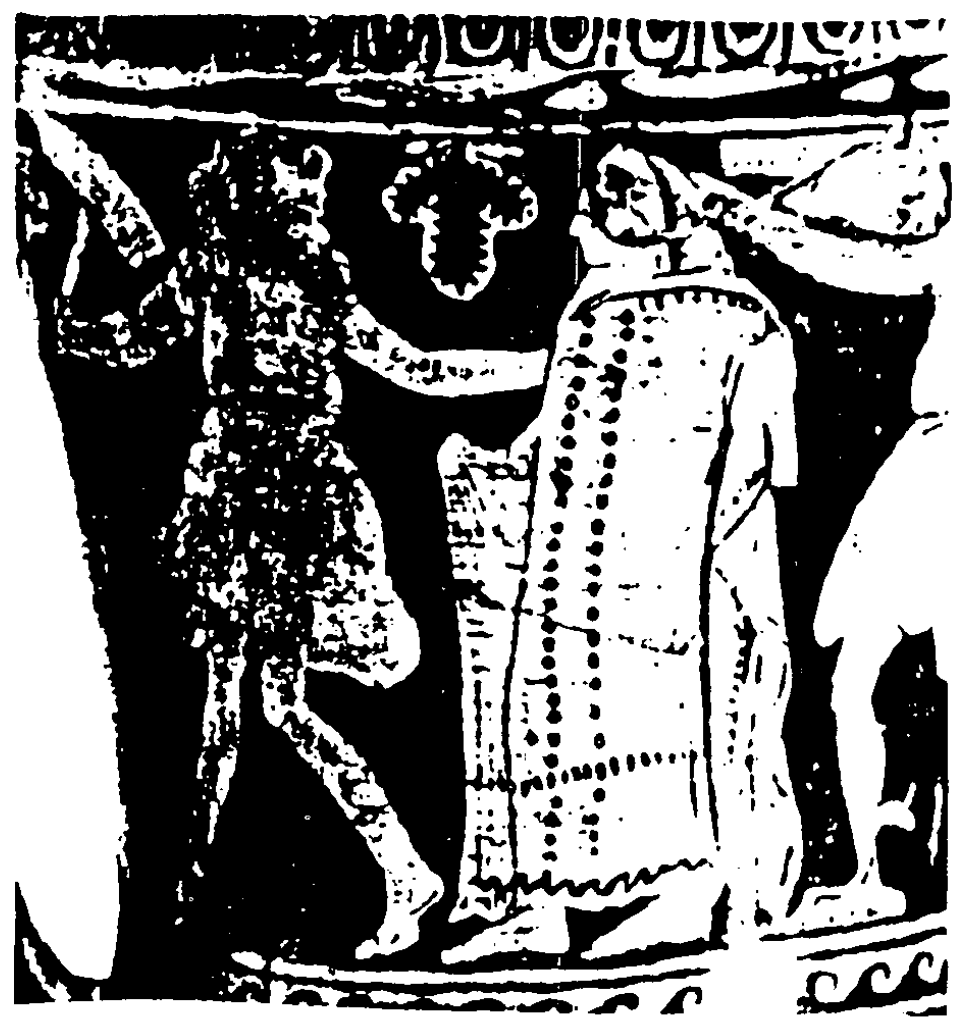

Figura 1: Morta iniciada sendo levada por dois demônios. Cratera etrusca em forma de cálice com figuras vermelhas do $3^{\circ}$ quartel do século IV a.C. do Museu Cívico de Trieste, 2125 (in Lexicon Iconographicum Mythologiae Classicae, vol. III2, p. 232, $n^{\circ} 85$ ). 


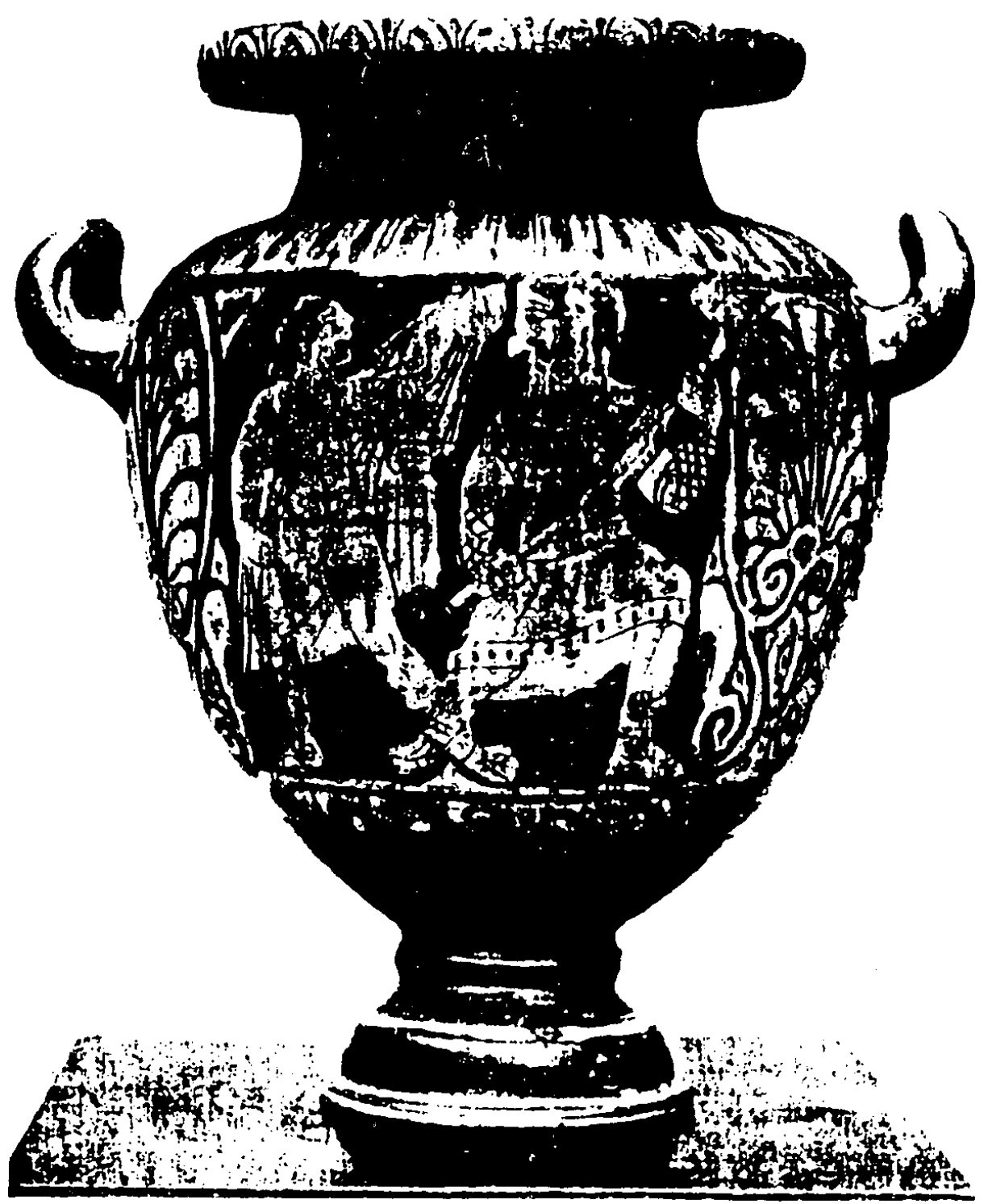

Figura 2: Morta iniciada abrindo o manto para o demônio Charum. Stamnos etrusco com figuras vermelhas da metade do século IV a.C. do Museu Cívico de Trieste, 7630 (in DE RUYT, F. Archeologia Classica XV: 97-101, 1985). 


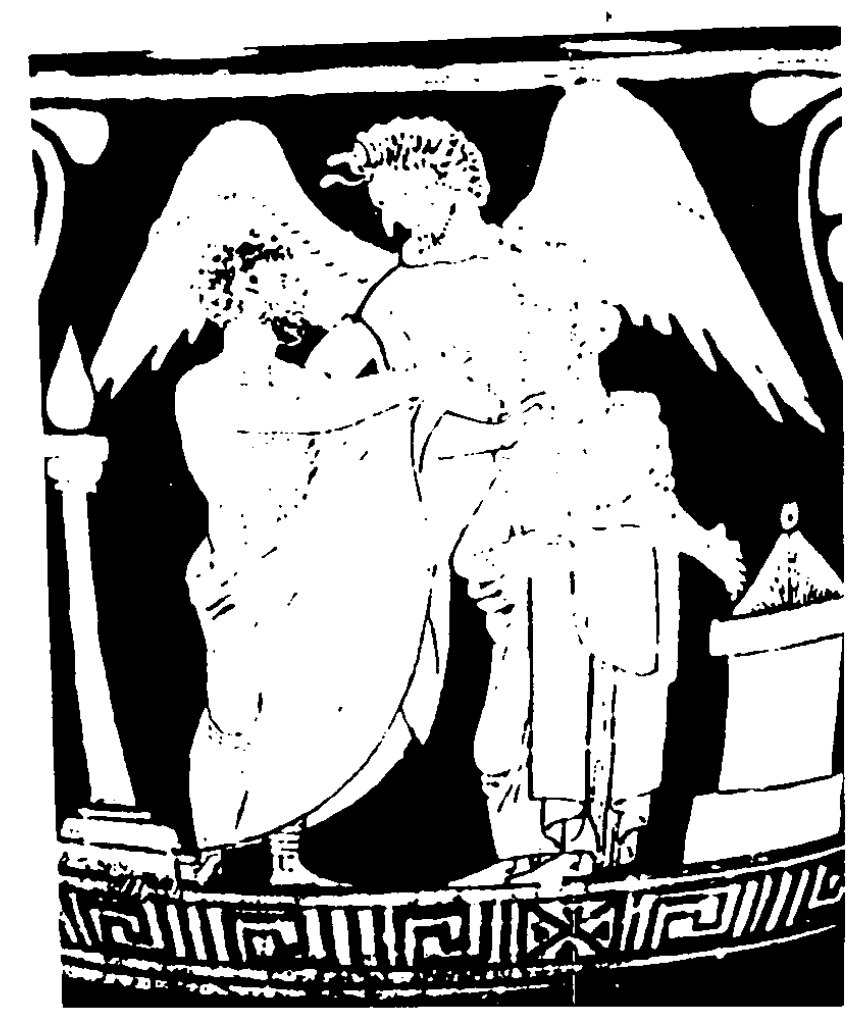

Figura 3: Despedida de Alceste e Admeto. Skyphos etrusco com figuras vermelhas de 330 a.C. do Museum of Fine Arts de Bostom, 97372 (in BEAZLEY, J. D. Etruscan Vase Painting, London, 1947, pr. 37).

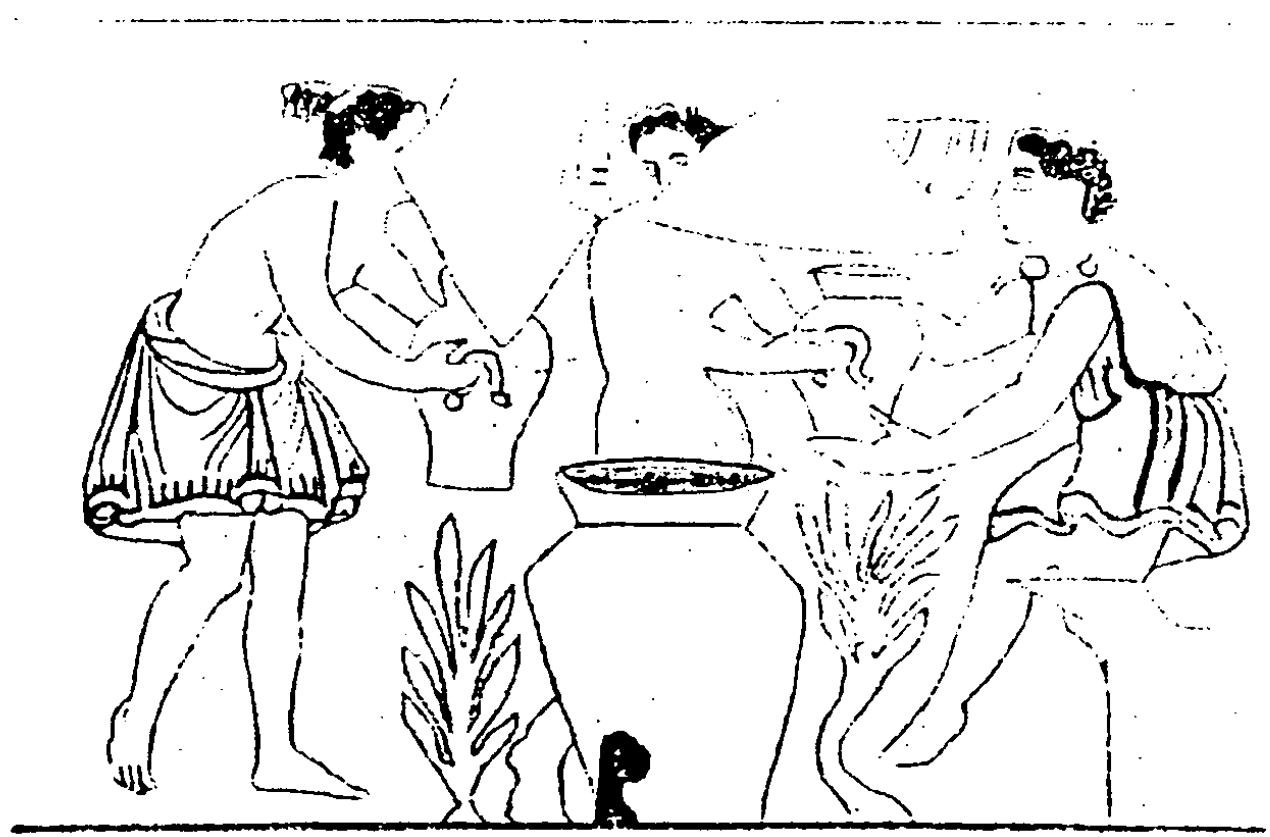

Figura 4: Danaídes enchendo um vaso sem fundo. Stamnos etrusco com figuras vermelhas do final do século IV a.C. do Museu Archeológico de Florença, 4128 (in BEAZLEY, J. D. Ibid., pr. 1I). 